\title{
Correspondence
}

\section{The rights of patients regarding ethnic monitoring}

Sir: I read with interest the letter from $\mathrm{Dr}$ Azuonye (Psychiatric Bulletin, 1994, 18, 649650) regarding ethnic monitoring.

The clinic in which I work serves one of the most multi-cultural populations in the country. The responsible NHS trust is introducing monitoring by showing patients a prompt card' with a list of 11 ethnic categories into which they are asked to classify themselves. The stated aim of this monitoring is "to be sure that our services are free from prejudice, so that everyone can use them equally and easily". If no ethnic choice is selected at first interview we are asked to repeat the above procedure at every subsequent patient contact. Although the expensively produced guides for clinicians using the card state that the patient may refuse to answer ethnic questions, there is no communication to patients on the card that they need not answer or that if they refuse, their care will be unaffected.

Patients may see psychiatrists because they have distressing symptoms which they regard as having little connection with ethnicity. Alternatively they may percetve their ethnicity as being of great importance in the way they and society see them and intimately connected with their life concerns. In the former situation questions on race may be experienced by them as irrelevant and in the latter as attacking.

Even if the measurement of ethnic groupings had some kind of proven internal validity, it is a simplistic assertion that, for example, if more Asian patients were referred to our clinic, racial prejudice, whether it be our own or that of the local community, had been overcome. Apart from the racism inherent in labelling others by ethnicity, it is a crude form of process audit masquerading as some measure of the quality of patient care. We as psychiatrists are increasingly being pressed by purchasers of health care to measure quantity as though it were equitvalent to quality of psychiatric care. Such matters as ethnicity are complex and cannot be reduced to numbers and categories.

Paul Foster, Willesden Centre for Psychological Treatment, Harlesden Road, London NW 10

\section{AIDS education}

Sir: The article by Dunn (Psychiatric Bulletin, 1994, 18, 575-576) lllustrates two separate approaches to AIDS education. While the Sunday Times is criticised for promoting a debate which questions accepted wisdom, the Brazallians are congratulated for promoting a message that "sex is good for physical and mental health" and "safe with a condom."

Tragically while the evidence that a heterosexual epidemic is taking hold in Brazil appears well substantiated, the evidence is that the Brazilian statements about condoms being "safe" are not correct.

The World Health Organization estimates that condoms only reduce infectivity of AIDS by a factor of 0.42 (Kelly, 1992). The report states that the latex used in condoms used in the West contain pores that are larger than the virus itself. If Brazilian condoms are indeed made of poorer quality latex then they will leak the virus even more. The fatlure rate in terms of conception with condoms is around $3.6 \%$ (Vessey et al, 1982) and higher for casual encounters. Given that women are fertile for less than $25 \%$ of the month and sperms are so much larger than the AIDS virus it can be seen that the condom is far from being a complete protection against the AIDS virus.

Commendable openness would therefore dictate that sex with a condom be described as "safer" or "less dangerous" but not "safe". If public health education campaigns continue to suggest that sex with anyone is safe provided a condom is used then we can only expect that the heterosexual epidemic will not be contained.

KeuLY, J. (1992) Promoting sexual health. Brttish Medical Joumal S00, 363.

VEssey, M., Lawress, M. \& Yeates, D. (1982) Efficacy of different contraceptive methods. Lancet, 1, 841-842.

AdRIAN TRELOAR, The Maudsley Hospttal, London SE5 8AZ

\section{Expanding poychiatrists' role in the} undergraduate medical curriculum

Sir: We echo Sensky's suggestion (Psychiatric Bulletin, 1994, 18, 557-559) that psychiatrists have a greater role to play in the increasingly overcrowded and technologised medical 